\title{
Augmented Reality Mobile Learning System: Study to Improve PSTs' Understanding of Mathematical Development
}

\author{
https://doi.org/10.3991/ijim.v14i09.12909 \\ Mohammad Faizal Amir( $\left.{ }^{\varpi}\right)$, Novia Ariyanti, Najih Anwar \\ Universitas Muhammadiyah Sidoarjo, Sidoarjo, Indonesia \\ faizal.amireumsida.ac.id \\ Erik Valentino \\ STKIP Bina Insan Mandiri Surabaya, Surabaya, Indonesia \\ Dian Septi Nur Afifah \\ STKIP PGRI Tulungagung, Tulungagung, Indonesia
}

\begin{abstract}
Augmented Reality research in mobile learning systems so far have not especially to improve Preservice Students Teachers' (PSTs) geometry understanding in mathematical development. Studies conducted in this study basically use a case study. This research aims to develop a mobile augmented reality system for PSTs learning so that it can be used to improve PSTs understanding of mathematics development includes doing, image-making, an image having, property noticing, formalizing, observing, structuring and inventing. In this development, PSTs can understand the understanding of the geometry transformation is a translation, reflection, rotation, and dilatation.
\end{abstract}

Keywords-Mobile systems, augmented reality, understanding mathematics, geometry transformation.

\section{Introduction}

In PISA 2015 mathematics assessed as minor domains, providing the opportunity to make comparisons of student performance over time. The results of preliminary field studies, mathematical understanding of geometry Preservice Student Teachers (PSTs) 20 of 36 in Universitas Muhammadiyah Sidoarjo have difficulty in solving mathematical understanding of geometry.

The development of learners by understanding participants [1] includes doing, image-making, an image having, property noticing, formalizing, observing, structuring, and inventing, linking concepts, ideas, facts, or mathematics procedures. Results of research by [2], [6] shows the importance of understanding the development problems of geometry PSTs that many of the teachers or prospective elementary school teachers do 
not have the concept of a strong understanding of geometry. While the PSTs' understanding relies on teachers' understanding of their own, therefore, the problem of understanding the development of geometry at PSTs should look for solutions.

For PISA 2015, the computer is the primary model for various domains, including an understanding of mathematical geometry. In the 4.0 era, as now, the development of Mobile-based Augmented Reality into learning technology revolution by providing a virtual information display geometry objects are more real in view space (spatial) [7], [8], The results showed Application of Augmented Reality in learning shown to improve the development of the learning outcomes of PSTs [9], [11], However, studies have not been especially Augmented Reality to improve PSTs understanding of the development and mobile learning systems that have not been made systematically developed according to the needs of PSTs. Therefore, researchers are interested in developing mobile learning system based on Augmented Reality, so understanding the mathematical geometry PSTs better suit the development of the industrial revolution 4.0 that demanded all aspects of fieldwork including in the field of education to develop learning-based "concept of the Internet of Things (IoT) ".

From the background that has been described can be taken the formulation of the problem underlying this study, namely: 1 . How is the development of mobile-based learning with augmented reality to the understanding of mathematical geometry PSTs? 2. How PSTs discover mathematical understanding through the process of making media augmented reality?

\section{Methods}

The participants of this study were 36 PSTs at Muhammadiyah University, Sidoarjo, Indonesia. The data collected are taken from a survey of lecturer and PSTs, focus groups, classroom observations of teaching sequence of tasks, and samples of PSTs' work. Studies conducted in this study basically uses a case study.

Qualitative methods in this study use a case study [12] and can be viewed as a "case study instrumental" because in this study wanted to gain more insight into how development and yield enhancement of understanding of mathematics when using mobile media system, especially on the transformation geometry. The level of understanding of PSTs is categorized by Pirie-Kieren's theory [5].

The study design using video recording as a means of data collection, and use the footage as the data to be analyzed. Video data is equipped with paper and record observations, to help have a more complete record of what is observed (and recorded) in each session. Several small groups of PSTs were recorded on video during a certain time span when they work mathematically.

Pretest and posttest standards-based mathematics developed by a team of researchers awarded with pencil and paper to each PSTs before and after the implementation of each unit. Pretest and posttests developed through the iterative process involving a review of lessons, consultations with the author of the lesson, the collection of assessment items that exist after the review state standardized tests, textbooks, and revision. PSTs performance on the math test WISEngineering state standards and samples collected 
for a random PSTs from the same district. We conducted semi-structured interviews of PSTs and teachers after the implementation of each unit to investigate attitudes towards engineering and the WISEngineering unit. The following sections describe in more detail the content ratings.

\section{Results and Discussion}

\subsection{Development of mobile systems}

This research aims to develop a mobile augmented reality system for PSTs learning so that it can be used to improve student understanding of mathematics development includes doing, image-making, an image having, property noticing, formalizing, observing, structuring and inventing. In this development, PSTs can know the understanding of the geometry transformation is a translation, reflection, rotation, and dilatation.

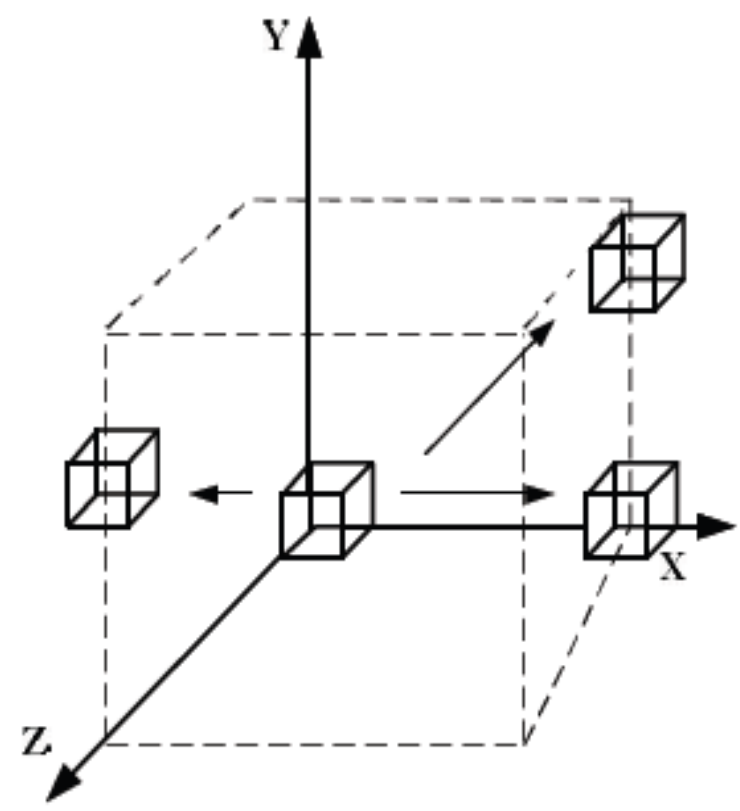

Fig. 1. A preliminary overview of the $3 d$ on $X Y Z$ axes

Figure 1 shows a preliminary overview of $3 \mathrm{~d}$ on XYZ axes for a higher PSTs made they can more understanding. In the process of translation, a translated object used by several provisions in accordance with the PSTs worksheets were prepared. At the PSTs worksheet, PSTs was asked to translate the object with the provisions.

Let us assume that we want to translate the point $\mathrm{P} \delta \mathrm{x}$ assistance in parallel with the $\mathrm{X}$-axis, and the distance $\delta \mathrm{y}$ in parallel to the $\mathrm{Y}$-axis. This transformation is accomplished by the addition. The results of the transaction are illustrated in Figure 2. 


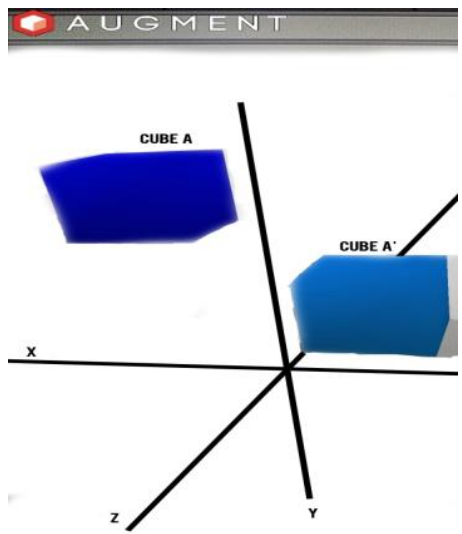

Fig. 2. Use media during the translation process

Figure 2 shows the translation of one picture. After explaining why it works in favor of homogeneous coordinates, we proceeded to the $3 \mathrm{D}$ space using this representation. Thus, the translation of the point $\mathrm{P}$ by the vector must show in Figure 3 performed by defined below $\mathrm{T}_{3 \mathrm{t}}$ following matrix shown in Figure 4.

$$
\mathrm{d}=\left|\begin{array}{c}
\delta x \\
\delta y \\
\delta z \\
1
\end{array}\right|
$$

Fig. 3. The point $\mathrm{P}$ on the image translation process

$$
T_{3 t} \boldsymbol{P}=\left|\begin{array}{cccc}
1 & 0 & 0 & \delta x \\
0 & 1 & 0 & \delta y \\
0 & 0 & 1 & \delta z \\
0 & 0 & 0 & 1
\end{array}\right|\left|\begin{array}{c}
x \\
y \\
z \\
1
\end{array}\right|=\left|\begin{array}{c}
x+\delta x \\
y+\delta y \\
z+\delta z \\
1
\end{array}\right|
$$

Fig. 4. The Test of transform

In the process of reflection, the object that is used is reflected by several provisions in accordance with the PSTs worksheets were prepared. At the PSTs worksheet, PSTs is required to object to the provisions reflected. In the process of using the tools of reflection mirrors to get a good reflection result by looking at the object of reflection in the mirror.

In the dilation process, an object used by the dilatation process several provisions in accordance with the PSTs worksheets were prepared. At the PSTs worksheet, PSTs is required to object to the provisions dilatation.

The matrix Ts defined by Equivalent (1) performs scaling about the origin. When Sx $=$ Sy, we say that the scaling is uniform. An example is shown in Figure 6, object 1 and object 2 are similar. Other terms used for this particular transformation are homothety or homothecy. 


$$
T_{s}=\left|\begin{array}{cc}
S_{x} & 0 \\
0 & S_{y}
\end{array}\right|
$$

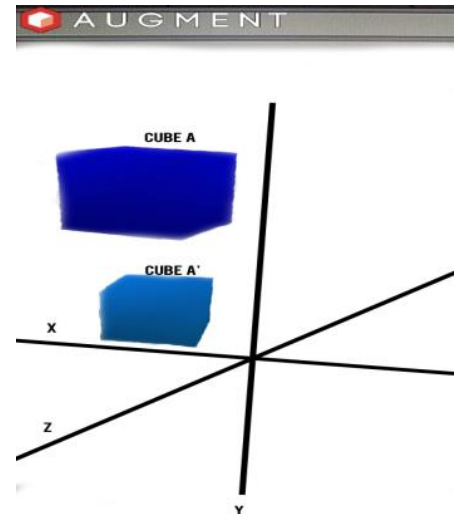

Fig. 5. Use media during the dilatation process

\subsection{Analysis and exploration understanding of mathematics}

The results of the use of the mobile system in the mathematical understanding of PSTs increased from before to after using a mobile system using the mobile system. Explain and calculate mathematical understanding is a complex and challenging problem. This study extends the work of Pirie and Kieren in describing the growth of mathematical understanding and therefore helps to understand a little better understanding [5].

This study focuses on the use of mobile augmented reality-based system in the growth of mathematical understanding of PSTs and details of the action which consists of translation, rotation, and dilation. The results of the use of the mobile system can be seen in Figure 7 the difference between the two answers to PSTs by way of their respective understanding of mathematical geometry. In the first answer, the PSTs do not show the level of image-making and image having. He directly answered the question with a formula that he knew without using a step by step according to the level of understanding of mathematical geometry.

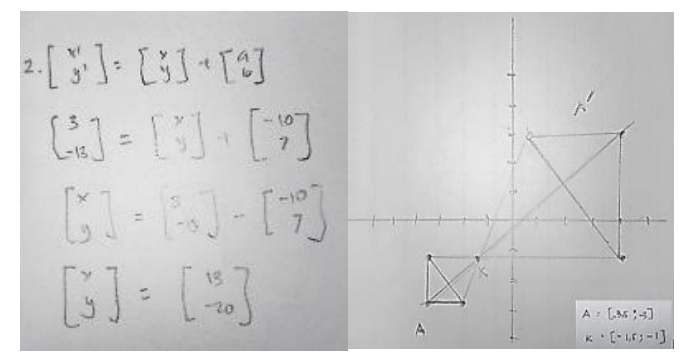

Fig. 6. Results answer PST of dilatation 
As for the answer to both PSTs described the process of dilatation of the questions so that the PSTs does in order by level geometric mathematical understanding. Namely through doing by looking for known, then to the level of image-making and imagedoing. After carrying out image-making and image having founded the result of dilatation of the wake.

Thus, the presence of mobile augmented reality-based system as part of the actions of each PSTs is not surprising. The results of each PSTs in each activity showed satisfactory results. So in this study with more emphasis on the mathematical understanding of each activity performed of translation, rotation, until dilatation of the transformation geometry by PSTs. Although beyond the scope here to regulate the relationship between every category, it is meant to discuss the relationships and links that have been shown by this study as very important in the process of refolding and the associated growth of mathematical understanding.

\subsection{Leveling mathematical understanding by pirie-kieren's theory}

Level 1 - Doing: The first level is a primitive knowledge that refers to previous knowledge of PSTs brought to the context. At this level, PSTs are using the system mobile to understand knowledge about the process initially where mobile use system if PSTs has difficulty beginning or not.

Level 2 - Image-making: The second level is the making of the picture. PSTs make a difference in previous knowledge and use it in new ways. At the time of the mobile system are used PSTs also learns something new to learn about new ways of transformation geometry circuitry.

Level 3 - Image having: The third level is to have a picture. PSTs makes a picture of a topic in mind. Overview of this topic written into the PSTs worksheet prepared so that PSTs do not forget about the image of the geometry transformation topics that have been previously contemplated by the PSTs.

Level 4 - Property noticing: The next level is the attention to their properties; properties constructed image identified at this level. At this level represents the construction of an understanding of the geometry transformation to translation, reflection, and dilation of the construction that has a different understanding. Moreover, the use of other tools during mobile use of the system is mathematical understanding PSTs.

Level 5 - Formalizing: At the level of formalization, methods, rules, or property generalized from the property.

Level 6 - Observing: Learners say and reveal about the concept of a formalized at the level observed.

Level 7 - Structuring: PSTs organizes a formal observation and thinking about it as a theory at the level of the arrangement.

Level 8 - Inventing. Level outermost creates: PSTs in inventory levels have "a full understanding of structured and therefore can break away from the prejudice that brings this understanding and creates new questions that grow into the entirely new concept". 
Table 1. The results of PSTs based on the average price level and the process of transformation geometry

\begin{tabular}{|l|c|c|c|c|c|}
\hline & Translational & Reflection & Dilatation & Total & \% \\
\hline Level 1 & 2 & 2 & 2 & 6 & 50 \\
\hline Level 2 & 2 & 3 & 2 & 7 & 58.3 \\
\hline Level 3 & 3 & 3 & 2 & 8 & 66.7 \\
\hline Level 4 & 2 & 3 & 4 & 9 & 75 \\
\hline Level 5 & 4 & 3 & 2 & 9 & 75 \\
\hline Level 6 & 3 & 4 & 3 & 10 & 83.3 \\
\hline Level 7 & 3 & 4 & 4 & 11 & 91.7 \\
\hline Level 8 & 2 & 3 & 3 & 8 & 66.7 \\
\hline Sum & 21 & 25 & 24 & & \\
\hline
\end{tabular}

The research results are described in Table 1 shows that the highest value on several levels seemingly at level 7 or structuring. These results explain the level of understanding of the mathematical structuring level during the use of the media to be effective. So that an increase in those levels. While on level 1 or the doing of the table results can be seen is the lowest score of all levels. It can be said that the PSTs do not have any special preparation to further understand the concept of the use of the system's augmented reality-based media.

The results of this study as well as other research on mathematical understanding where the results of the PSTs scores are not the primary outcome in the study. Because understanding the math assessment results can not be measured only by researches will but by several studies.

\subsection{Discussion}

As shown by the various results of PSTs activities, not all of the action folded back should lead to sustained growth in mathematical understanding, and this is a significant contribution of this research to the Pirie-Kieren's theory, and to our understanding of mathematics. Data from this study showed that if the multiplying into effective action for the PSTs, and to allow for continued growth as a result of their understanding that there are two main components of this to consider.

First, the actual form of the activity of the inner layer is used should be appropriate. In other words, a PSTs should be aware of (or help become aware through appropriate interventions) about the limitations of current understanding, in terms of mathematics, and the type of activity in the layers like what he did. or he must seek to extend this. For example, in striving to resolve a complex algebraic equation it may be necessary to fold back and collect his understanding of division of fractions to allow the equations to become simplified. However, if this understanding is not complete enough to be collected and then folds back and works on topics that may use numbers, it may be necessary to build a more complete understanding of fractions which can then be applied to the problem. 


\section{Conclusion}

This research aims to develop a mobile augmented reality system for PSTs learning so that it can be used to improve PSTs understanding of mathematics development includes doing, image-making, an image having, property noticing, formalizing, observing, structuring and inventing. In this development, PSTs can understand the understanding of the geometry transformation is a translation, reflection, rotation, and dilatation.

The research results showed that the highest value on several levels seemingly at level 7 or structuring. These results explain the level of understanding of the mathematical structuring level during the use of the media to be effective. So that an increase in those levels. While on level 1 or the doing of the table results can be seen is the lowest score of all levels. It can be said that the PSTs do not have any special preparation to further understand the concept of the use of the system's augmented reality-based media.

\section{$5 \quad$ References}

[1] S. E. Pirie, "Understanding: instrumental, relational, intuitive, constructed, formalised? How can we know?," Learn. Math., vol. 8, no. 3, pp. 2-6, 1988.

[2] H. Gülkılıka, H. H. Uğurlub, and N. Yürükc, "Examining students' mathematical understanding of geometric transformations using the pirie-kieren model," Kuram ve Uygulamada Egit. Bilim., vol. 15, no. 6, pp. 1531-1548, 2015.

[3] J. Gunčaga, Š. Tkačik, and K. Žilková, "Understanding of Selected Geometric Concepts by Pupils of Pre-Primary and Primary Level Education,” Eur. J. Contemp. Educ., vol. 6, no. 63, pp. 497-515, 2017.

[4] V. M. Kolar, T. Hodnik Čadež, and E. Vula, "Primary Teacher Students' Understanding of Fraction Representational Knowledge in Slovenia and Kosovo," Cent. Educ. Policy Stud. J., vol. 8, no. 2, p. 71, 2018. https://doi.org/10.26529/cepsj.342

[5] L. C. Martin, "Folding back and the dynamical growth of mathematical understanding: Elaborating the Pirie-Kieren Theory," J. Math. Behav., vol. 27, no. 1, pp. 64-85, 2008. https://doi.org/10.1016/j.jmathb.2008.04.001

[6] A. G. Wilhelm, "Mathematics teachers' enactment of cognitively demanding tasks: Investigating links to teachers' knowledge and conceptions," J. Res. Math. Educ., vol. 45, no. 5, pp. 636-674, 2014. https://doi.org/10.5951/jresematheduc.45.5.0636

[7] C.-M. Chen and Y.-N. Tsai, "Interactive augmented reality system for enhancing library instruction in elementary schools," Comput. Educ., vol. 59, no. 2, pp. 638-652, 2012. https://doi.org/10.1016/j.compedu.2012.03.001

[8] M. E. C. Santos, A. Chen, T. Taketomi, G. Yamamoto, J. Miyazaki, and H. Kato, "Augmented Reality Learning Experiences: Survey of Prototype Design and Evaluation," IEEE Trans. Learn. Technol., vol. 7, no. 1, pp. 38-56, 2014. https://doi.org/10.1109/tlt.2013.37

[9] M. F. Amir, N. Fediyanto, C. Chotimah, and H. E. Rudiyanto, "Developing 3Dmetric Media Prototype through a Hypothetical Learning Trajector to Train Students Spatial Skill," J. Adv. Res. Dyn. Control Syst., vol. 10, no. 02-Special Issue, pp. 1537-1542, 2018. https://doi.org/10.31227/osf.io/vmk45 
[10] F. D. Pace, F. Manuri, and and A. Sanna, "Augmented Reality in Industry 4 . 0," Am. J. Comput. Sci. Inf. Technol, vol. 6, no. 1, pp. 1-7.

[11] P. Salinas and R. Pulido, "Understanding the Conics through Augmented Reality," EURASIA J. Math. Sci. Technol. Educ., vol. 13, no. 2, pp. 341-354, 2017. https://doi.org/10.12973/eurasia.2017.00620a

[12] J. W. Creswell, Educational research: Planning, conducting, and evaluating quantitative and qualitative research, vol. 4. 2012.

\section{Authors}

Mohammad Faizal Amir is a lecturer and assistant professor in the education department of elementary school teachers at the Universitas Muhammadiyah Sidoarjo until now. He is now pursuing a doctoral degree in mathematics education at the Universitas Negeri Malang, Indonesia. Topics that are often used as research are about mathematics education in various fields, such as learning media in technology, understanding, and problem-solving.Email: faizal.amir@umsida.ac.id

Novia Ariyanti is a lecturer in the engineering faculty of the Universitas Muhammadiyah Sidoarjo until now, the area of research interest is the use and development of technology related to mathematics learning.

Najih Anwar is a lecturer and associate professor in the Islamic religion faculty of the Muhammadiyah University of Sidoarjo starting in 2006, the area of research interest is student psychology in learning

Erik Valentino is a lecturer in the Department of Mathematics Education at STKIP Bina Insan Mandiri Surabaya from 2014 until now. He is now pursuing a doctoral degree in Mathematics Education at Surabaya State University, Indonesia. Research topics are often used are mathematics education such as misconception, mathematics literacy, learning media.

Dian Septi Nur Afifah is a lecturer in the Mathematics education department teachers at STKIP PGRI Tulungagung from 2011 until now. She was in the doctorate mathematics education field. Research topics are often used are mathematics education such as understanding in use learning media.

Article submitted 2019-12-28. Resubmitted 2020-02-15. Final acceptance 2020-02-20. Final version published as submitted by the authors. 